\title{
Prevalence of Postpartum Depression and Risk Factors in Woman who did Delivery in University Clinical Center of Kosovo Clinic of Gynecology and Obstetric
}

\author{
Bujar Obertinca ${ }^{1}$, Afrim Dangellia ${ }^{2}$, Myrvete Pacarada ${ }^{3}$, Albiona Beselica Beha ${ }^{3}$, Florim Gallopeni ${ }^{3}$, \\ Nazmie Ibishi ${ }^{1}$ \\ ${ }^{1}$ Institute of Forensic Psychiatry of Kosovo, University Clinical Center of Kosova, Pristina, Kosovo \\ ${ }^{2}$ University Hospital Center "Mother Theresa" Tirana, Albania \\ ${ }^{3}$ Clinic of Gynecology and Obstetric, University Clinical Center of Kosovo, Pristina, Kosovo \\ ${ }^{4}$ Qeap-Himerer, Pristina, Kosovo
}

\begin{abstract}
Postpartum depression (PPD) is a serious public health concern and this condition has become more common in routine obstetric care, while data are now more readily available to assist researchers in identifying patient characteristics that may be associated with increased risk of PPD. Subjects of this study were women who gave birth between January 2012-December 2013, at Clinic of Gynecology and Obstetrics in Prishtina, 385 women, hospitalized inpatients prospectively fulfilled the selection criteria and completed self-reporting questionnaires 2-3 days after childbirth using Adult Self Report/Adult Behavior Checklist (ASR/ABCL, 2003).Inpatients characteristics included the method of delivery mode and socio demographic data. Results showed that prevalence of depression was $17.6 \%$ in the sample of 385 subjects with mean age $28,8 \pm 5,6$, years of education $11 \pm 2,8$, mostly living in rural area $53,9 \%$, and underwent caesarean section delivery in 58,3\% of cases. Our findings showed significant differences on PPD because of delivery mode, experienced stress during pregnancy and place of living within family (extending \& nuclear family) as a risk factor for PPD.
\end{abstract}

Keywords: PPD, Stress, delivery mode, family, risk factors

\section{Introduction}

Postpartum depression (PPD) is a serious public health concern and this condition has become more common in routine obstetric care, while data are now more readily available to assist researchers in identifying patient characteristics that may be associated with increased risk of PPD. There is a high prevalence of PPD among new mothers 10-15\% (Dorothy K. Sit and Katherine L. Wisner, 2009). However, there are few studies available focused on investigating the prevalence of depressive symptoms among pregnant women and after delivery period, and are different factors that can impact on PPD.

In many industrialized countries postpartum depression has become even more common complication of childbirth (Dominic et al, 2004). Epidemiological studies generally show that the prevalence of postpartum depression is in the range of 10-15\% (Appleby and others, 1996; Warner and others, 1996; Swain, O'Hara, Starr and Gorman, 1997; Brugha et al, 1998; Lee et al, 2001; Chandran et al, 2002). Lee and Chung (2007), in their study provided the definition of PND is characterized largely by "a mood of despair, weeping, lack of motivation, social withdrawal, insomnia, poor appetite, impaired concentration, feelings of inadequacy and helplessness 'and the feeling of detachment from the baby and the social world, and often with' physical symptoms such as pain, headache and backache.
Two main symptoms of postpartum depression, which should focus more attention and care to observe, are consistency [continuity] status without humor and lack of joy, satisfaction or expectations to see or to do new things ( Whooley et al, 2007). Symptoms include difficulty to sleep, early awakening, fatigue, loss of weight, loss of appetite, feelings of guilt, feelings of inadequacy, helplessness and hopelessness, anger or emptiness. Ultimately, though postpartum depression affects all women, regardless of ethnicity or social class, other factors of risk contributing to the development include social exclusion, deprivation, and the complexity of the relationship (Patel, Rodrigues, and Desouza, 2002).

Usually when studies are conducted the interpretation of etiological factor of psychiatric illnesses, are emphasis on the importance of addressing the complex factors that affect concerned disease, they are always stressed in that way that we cannot assume that there is only one reason or factor. Genetic studies and biological mood disorders show that they are complex disease, and even if an individual has a genetic weakness or predisposition for the development of depression, there always should be factors of personal experience and environment which interact between them causing disease. (Dubovsky \& Buzan, 1999).

Therefore, it is very likely that a number of these factors play an important role in the development of postpartum depression. The main risk factors include a previous history 


\section{International Journal of Science and Research (IJSR) \\ ISSN (Online): 2319-7064 \\ Index Copernicus Value (2013): 6.14 | Impact Factor (2015): 6.391}

of depression, relationship not good marriage, hormonal changes in the body, anxiety, prenatal depression, prenatal able prolonged 'baby blues', temperament of the baby, the stress of life, social support, self-assessment, socioeconomic status, stress levels to infant care (Beck, 2001). In the first days after birth risk factors include a difficult birth, a history of abuse, low family income and lower professional status. (SIGN 2002).

\section{Methods}

Parts of this study were women who gave birth between January 2012-December 2013, at Clinic of Gynecology and Obstetrics in Prishtina in University Clinical Center of Kosova. In total they where 385 woman's who were hospitalized, all of them where interview by the trained participants of psychiatric nurses/psychologist. Who took part in a 2-day interviewing skills workshop at the Clinic of Psychiatry at the University Clinical Center of Kosova. The workshop was run by experienced psychologists and psychiatrist employed at this department. Training was considered necessary due to the sensitive nature of the questions asked during the questionnaire-guided interview. Participants were informed about the objectives of the survey and ensured anonymity. Only women who were willing to participate in the survey were interviewed and they fulfilled the selection criteria and completed selfreporting questionnaires 2-3 days after childbirth using Adult Self Report/Adult Behavior Checklist (ASR/ABCL, 2003). Inpatients characteristics included the method of delivery mode and socio demographic data.

Written informed consent was provided by each participant who agreed to take part. Interviews were conducted by carefully trained interviewers and lasted between 20 minutes and 45 minutes averaging 30 minutes.

To collect data in research we used Adult Self Report ASEBE. In the first part questionnaire was completed with questions on demographic data for research interests, such as the number of pregnancies, number of children, family status, social status, residence, etc.

ASR questionnaire completed by adults and reported adaptive functions, and substance abuse problems. This form is valid for assessment of adult mental health, family therapy, forensic, counseling, substance abuse, etc.

ASR estimates: Adaptive degree of functionality: Friends, spouse / partner, family, work, education. The degree of syndromes: Anxiety / depressive, withdrawn, somatic complaints, problems with thinking, attention problems, aggressive behavior, rule-breaking behavior.

DSM- oriented scales: Depressing Problems, Problems Anxiety, somatic problems, evasive personality, attention deficit / hyperactivity and problems with antisocial personality problems.

Scale of substance abuse, tobacco, drugs and alcohol.

ASR questionnaire - is used in a significant number of research works and reliability and validity are well documented. The questionnaire was translated and adapted in Albanian language, while preserving as much of the original meaning of the original questionnaire items, but has not yet become his validation.

\section{Results}

Results showed that prevalence of depression was $17.6 \%$ in the sample of 385 subjects with mean age $28,8 \pm 5,6$, years of education $11 \pm 2,8$, mostly living in rural area 53,9\%, and underwent caesarean section delivery in $58,3 \%$ of cases. Delivery mode is significantly associated with PPD, and analysis of t- test showed that natural birth comparing to cesarean section showed significantly higher level of PPD, $\mathrm{p}=, 02$ value, results showed that natural birth has $\mathrm{M}=6.81$ with $\mathrm{SD}=4.96$, comparing to women who give birth with cesarean section with $\mathrm{M}=5,77$ and $\mathrm{SD}=4.24$. Women who live in core family showed significantly higher level of PPD, $\mathrm{p}=.05$, comparing to women who live in extended family, $\mathrm{t}-$ test showed that woman who live in core family has $\mathrm{M}=6.74$ and $\mathrm{SD}=4.91$, comparing to women who live in extended family with $\mathrm{M}=5.81$ and $\mathrm{SD}=4.29$.

\begin{tabular}{|c|c|c|c|c|}
\hline & \multicolumn{4}{|c|}{ Depression } \\
\hline & $\mathrm{M}$ & SD & $\mathrm{t}$ & $\mathrm{p}$ \\
\hline \multicolumn{5}{|l|}{ Family } \\
\hline $\begin{array}{l}\text { Extended } \\
\text { Core } \\
\text { Stress }\end{array}$ & $\begin{array}{l}5.81 \\
6.74\end{array}$ & $\begin{array}{l}4.29 \\
4.91\end{array}$ & 1.96 & $0.5^{*}$ \\
\hline Po & 7.41 & 5.7 & 1.91 & $.05 *$ \\
\hline Jo & 6.01 & 4.39 & & \\
\hline \multicolumn{5}{|l|}{ Delivery mode } \\
\hline Natural & 6.81 & 4.96 & 2.27 & $.02 *$ \\
\hline Cesarean section & 5.77 & 4.24 & & \\
\hline \multicolumn{5}{|l|}{ Smoking } \\
\hline Yes & 7.43 & 5.7 & 2.33 & $.02 *$ \\
\hline No & 5.94 & 4.3 & & \\
\hline
\end{tabular}

Delivery mode is significantly associated with PPD, and analysis of t- test showed that natural birth comparing to cesarean section showed significantly higher level of PPD, $\mathrm{p}=, 02$ value, results showed that natural birth has $\mathrm{M}=6.81$ with $\mathrm{SD}=4.96$, comparing to women who give birth with cesarean section with $\mathrm{M}=5,77$ and $\mathrm{SD}=4.24$. Women who live in core family showed significantly higher level of PPD, $\mathrm{p}=.05$, comparing to women who live in extended family, $\mathrm{t}$ test showed that woman who live in core family has $\mathrm{M}=6.74$ and $\mathrm{SD}=4.91$, comparing to women who live in extended family with $\mathrm{M}=5.81$ and $\mathrm{SD}=4.29$. Women who declare that smoked during pregnancy showed significantly higher level of PPD, $\mathrm{p}=.02$, comparing to women who didn't smoke during pregnancy.

t-test showed that women who smoked has $\mathrm{M}=7.43$ and $\mathrm{SD}=5.7$, comparing to women who didn't smoke with $\mathrm{M}=5.94$ and $\mathrm{SD}=4.3$. Women who declared that 


\section{International Journal of Science and Research (IJSR) \\ ISSN (Online): 2319-7064 \\ Index Copernicus Value (2013): 6.14 | Impact Factor (2015): 6.391}

experienced stress during pregnancy showed significantly higher level of PPD, $p=.05$, comparing to women who didn't experienced stress during pregnancy. T-test showed that women who experienced stress has $\mathrm{M}=7.41$ and $\mathrm{SD}=5.7$, comparing to women who didn't experience stress with $\mathrm{M}=6.01$ and $\mathrm{SD}=4.39$.

Table, 1. Linear regression, predicted model

\begin{tabular}{lccccc}
\hline Model & \multicolumn{2}{c}{$\begin{array}{l}\text { Unstandardized } \\
\text { Coefficients }\end{array}$} & \multicolumn{3}{c}{$\begin{array}{c}\text { Standardized } \\
\text { Coefficients }\end{array}$} \\
& \multicolumn{1}{c}{ B } & Std. Error & Beta & t & Sig. \\
\hline (Constant) & 10,865 & 2,055 & & 5,288 &, 000 \\
Family & 1,029 &, 471 &, 111 & 2,183 &, 030 \\
Delivery mode & 1,027 &, 476 &, 111 & 2,160 &, 031 \\
Stress & $-1,127$ &, 730 &,- 079 & $-1,545$ &, 123 \\
Smoking & 1,299 &, 633 &, 104 & 2,051 &, 041 \\
\hline
\end{tabular}

Dependent Variable: Depression

Linear Regression showed the model who can predict PPD, and those factors can be a risk factor for PPD, the factors who predicted the PPD and showed significant results are, type of family, delivery mode and smoking.

\section{Discussion and Conclusions}

Our study may be helpful in better understanding of female psychosocial problems in perspective of wanted, unwanted pregnancies and intentional interruption of the same and for the prospective planning of preventive intervention strategies in improving women's mental health in postwar conditions.

Studies in western countries generally report a higher incidence of psychiatric disorders in urban populations than rural populations. In contrast, our study found almost twice the prevalence of antenatal depression and anxiety among rural women as among urban women. This apparent contradiction may be explained by the unique environmental factors that pregnant women are exposed to in developing countries. In the cultural context of Kosovo, several social factors are worth mentioning. First, there is a very large gap in the standards of living and available facilities between rural and urban communities in developing countries, whereas this gap is not as large in developed countries. Rural women are less independent and play a lesser role in decision making than urban women. Rural settings also have an adverse effect on the mental health of pregnant women. These factors, in our opinion, are important contributors to the greater depression and anxiety among pregnant women in rural settings in our country. Developmental programs in

\section{Acknowledgment}

A lot of individuals and organizations have contributed during the planning and conduct of this research project in different ways. To list all would be impossible. However, we would like to thank University Clinical Center of Kosovo and Gynecological Obstetrical Clinic of Pristina for allowing us to conduct the study and allocating time for the rural communities may help reduce psychological morbidity in rural pregnant women.

An interesting finding in our study was the correlation between the occupation of pregnant women and depression and anxiety. In contrast to studies in western populations, which mention employment as a strong protective factor against major depression in pregnancy, our study found that pregnant women employed outside the home were actually more depressed and anxious than housewives. A study in Karachi, Pakistan also apparently contradicts our findings by concluding that housewives, in general, are more depressed than working women. Several factors might explain this contradiction. Most of these studies mention education as an important protective factor against antenatal anxiety and depression. Therefore, the lower educational level of housewives compared to working women was associated with higher levels of anxiety and depression. So even most of the working women may not have been educated highly enough for their employment status to have a positive effect on their mental health. In recent years economic crisis has increased and socioeconomic conditions have deteriorated in Kosovo, and these changes have led to increased stress and the pressures on working women to meet the economic needs of their household. It is also well documented that greater work stress can precipitate anxiety and depression in employed men and women. This increased stress, combined with the demands of pregnancy, might be responsible for greater depression and anxiety in working women compared to housewives, who are relatively protected from work stress.

These factors may contribute to a higher incidence of depression and anxiety. Effective family planning methods and the provision of safer abortion methods may reduce this problem.

Other factors such as harassment, a history of miscarriage and the unplanned vs. planned nature of the pregnancy were also significantly associated with antenatal anxiety and depression, and have been identified repeatedly in earlier studies.

We conclude that the most frequent emotional and psychological effects after abortion were: sleeping disorders repentance, anger, guilt and shame, loss of confidence, feelings of loneliness, food disorders, anxiety, and depression. These emotional effects can have a negative effect on planning pregnancy and holding other pregnancies. Therefore Gynecological Obstetrical Clinic in University Clinical Center of Kosova is recommended to insert the service of clinical psychology that will clarify and identify the riskiness of symptoms in these women in order to receive appropriate support and counseling.

research. We extend our gratitude to the data collectors , mothers and families who participated in this study.

\section{References}

[1] Lau Y, Wong DF, Chan KS. (2010, Aril 13). The utility of screaning for perinatal depression in the second trimester among Chinese: a three-wave prospective 
longitudinal study. (C. P. PubMEd, Ed.) Arch Women Ment Health, 153-164.

[2] Mbah AK, Salihu HM, Dagne G, Wilson RE, BruderK. (2013, Aprill 25). Exposure to enviromental tobacco smoke and risk of antenatal derpesion: application of latent variable modeling. Arch Womens Mental Health, 293-302.

[3] MeijerJL, Beijers C, van Pampus MG, Verbeek T, Stolk RP, Milgrom J, Bockting CL, Burger H. (2014, December). Predictive accuracy of Edinburgh postnatal depression scal assessment during pregancy for the risk of developing pospartum depressive simptoms: a prospective cohort study. BJOG, 1604-1610.

[4] Quelopana AM, Champion JD, Reyes-Rubilar T. (2011, October). Factors associated with postpartum depression in Chilean women. Health Care Women Int., 939-949.

[5] Sara Thurgood, Daniel M.Avery, Lloyda Williamson. (2009). Postpartum Depression. American Journal of Clincal Medicine, Six, 17-22

[6] Peen J, Schoevers RA, Beekman AT, Dekker J (2010) The current status of urban-rural differences in psychiatric disorders. Acta Psychiatr Scand 121: 84-93.

[7] Stewart RC, Umar E, Tomenson B, Creed F (2014) A cross-sectional study of antenatal depression and associated factors in Malawi. Arch Womens Ment Health 17: 145-154

[8] Fall A, Goulet L, Vézina M (2013) Comparative study of major depressive symptoms among pregnant women by employment status. Springerplus 2: 201

[9] Soomro RH, Riaz F, Naved S, Soomro FH (2012) Comparative Analysis of Depression among Housewives and Working Women in Bilal Colony of Kornagi Area Karachi.

[10] Melchior M, Caspi A, Milne BJ, Danese A, Poulton R, et al. (2007) Work stress precipitates depression and anxiety in young, working women and men. Psychol Med 37: 1119-1129.

[11] Westdahl C, Milan S, Magriples U, Kershaw TS, Rising SS, et al. (2008) Social Support and Social Conflict as Predictors of Prenatal Depression. Obs Gynecol 110: 134-140.

[12] Blackmore ER, Côté-Arsenault D, Tang W, Glover V, Evans J, et al. (2011) Previous prenatal loss as a predictor of perinatal depression and anxiety. $\mathrm{Br} \mathrm{J}$ Psychiatry 198: 373-378. 